\title{
MODEL MAGANG INDUSTRI GUNA PENCAPAIAN STANDAR KOMPETENSI LULUSAN FAKULTAS EKONOMI UNIVERSITAS NEGERI YOGYAKARTA
}

\author{
INDUSTRIAL INTERNSHIP MODELS FOR ACHIEVING THE COMPETENCE \\ STANDARDS OF FACULTY OF ECONOMICS YOGYAKARTA STATE UNIVERSITY \\ GRADUATES
}

Oleh:

Dhyah Setyorini

Staf Pengajar Jurusan Pendidikan Akuntansi Universitas Negeri Yogyakarta dhyah_setyorini@uny.ac.id

\section{Barkah Lestari}

Staf Pengajar Jurusan Pendidikan Akuntansi Universitas Negeri Yogyakarta barkahlestari@uny.ac.id

Purwanto

Staf Pengajar Jurusan Pendidikan Akuntansi Universitas Negeri Yogyakarta purwanto@uny.ac.id

Winarno

Staf Pengajar Jurusan Pendidikan Akuntansi Universitas Negeri Yogyakarta Winarno@uny.ac.id

\section{Endra Murti Sagoro}

Staf Pengajar Jurusan Pendidikan Akuntansi Universitas Negeri Yogyakarta endra_ms@uny.ac.id

\section{Rudi Prasetya}

Pendidikan Akuntansi Universitas Negeri Yogyakarta rudiprasetya2015@student.uny.ac.id

\section{Irfa Ummul Chasanah}

Pendidikan Akuntansi Universitas Negeri Yogyakarta irfaummul2015@student.uny.ac.id

\begin{abstract}
Abstrak
Penelitian ini bertujuan untuk menemukan model magang yang tepat untuk mencapai standar kompetensi dari Fakultas Ekonomi. Penelitian ini bisa dikategorikan sebagai penelitian dan pengembangan ( $\mathrm{R}$ and $\mathrm{D}$ ). Langkah-langkah penelitian $\mathrm{R}$ and $\mathrm{D}$ dibatasi pada tahap validasi desain produk yang dilakukan secara internal.

Data dalam penelitian ini menggunakan data kualitatif seperti saran dan masukan yang diberikan oleh pengawas magang dan pengguna. Data kuantitatif menggunakan kuesioner untuk menilai kelayakan model magang yang diusulkan kepada supervisor magang dan pengguna. Subjek penelitian ini adalah 41 siswa yang mengambil magang, pemangku kepentingan/pengguna, dan lembaga pendidikan tinggi. Objek penelitian adalah model industri magang yang akan ditinjau berdasarkan: jenis magang, kemampuan mentor dalam pengawasan, guru hadir, mentor magang di
\end{abstract}


lapangan, durasi magang, kesesuaian kurikulum PT dengan kebutuhan dunia kerja, proses meliputi pengelolaan magang, dan produk termasuk pengembangan keterampilan siswa.

Hasil penelitian menunjukkan bahwa model magang telah didominasi oleh model guru magang, tapi model magang yang diinginkan adalah sandwich. Berdasarkan tren di aspek-aspek kunci, menunjukkan bahwa aspek konteks, aspek desain kurikulum, aspek pengembangan keterampilan, dan aspek manajemen magang memiliki kecenderungan mengarah dari sedang sampai tinggi.

Kata kunci: Magang, Kompetensi, Aspek

\section{Abstract}

The research aimed to find a proper model apprentice in order to achieve the competency standards the of Faculty of Economics. This study could be categorized as a research and development. Although it was a research development, the research steps is limited to the validation stage of product design which is done internally.

The data in this study using qualitative data such as advice and input which is given by the internship supervisor and user. The quantitative data used questionnaire to assess the feasibility of proposed apprenticeship models to the internship supervisor and user. Subject of this study were 41 students who were taking internships, stakeholder or user, and higher education institutions. The object of research was a model of apprenticeship industry that will be reviewed based on: the type of internship, the ability of mentors in supervision, attendance teachers, mentors interns in the field, the duration of the internship, the suitability of the curriculum PT with the needs of the workforce, the process includes the management of apprenticeship, and the products include the development of skills of students,

The result showed that the model of apprenticeship had been dominated by the apprentice master models, but the desired internship models was a sandwich. Based on the trends in key aspects, showed that aspects of the context, aspects of curriculum design, the aspect of skill development, and management aspects of the internship had the tendency leads from moderate to high.

Keywords: Internships, Competence, Aspects

\section{PENDAHULUAN}

Pengimplementasian MEA tidak hanya membuka arus perdagangan bebas dan pasar modal tetapi juga membuka persaingan pasar kerja. Hal tersebut merupakan tantangan tersendiri bagai UNY untuk menghasilkan lulusan berkualitas. Kesiapan lulusan UNY berkompetisi di tingkat global ini menjadi salah satu tolak ukur keberhasilan UNY mencapai WCU.

Salah satu usaha UNY dalam menyiapkan lulusan yang berkualitas dan siap memasuki pasar kerja dengan melakukan perbaikan kurikulum. Perbaikan kurikulum selalu dilakukan agar kompetensi lulusan UNY memenuhi permintaan dunia kerja global. Pengimplementasian kurikulum 2014 berbasis KKNI (Kerangka Kualifikasi Nasional Indonesia) diharapkan dapat menunjang kualitas lulusan UNY (kompetensi) siap bersaing di pasar tenaga kerja global.

Terkait dengan adanya kurikulum berbasis KKNI dan visi-misi UNY menuju WCU, matakuliah magang menjadi matakuliah yang wajib ditempuh oleh mahasiswa lulusan UNY. Matakuliah ini menjadi salah satu upaya UNY untuk meningkatkan kompetensi lulusannya memasuki dunia kerja. Magang industri diharapkan mampu mengurangi kesenjangan antara teori dan praktik yang dimiliki lulusan UNY. Magang industri akan memberikan wawasan yang luas bagi mahasiswa bagaimana suasana dunia kerja, sehingga ketika lulusan siap masuk dunia kerja tidak lagi merasa canggung. Dengan kata lain, magang industri diharapkan dapat meningkatkan kesiapan kerja dari lulusan UNY. 
Beberapa permasalahan yang dialami Fakultas Ekonomi dalam menerapkan magang industri selama ini antara lain: 1). belum tersedianya model magang industri yang tepat untuk diberlakukan, 2). Belum ada pedoman pelaksanaan magang industri. Penyelenggaraan matakuliah magang tidak sama antara satu jurusan dengan jurusan lain, sebagai contoh: magang indsutri dilaksanakan bervariasi antara semester lima sampai dengan tujuh. Adapun khusus jurusan kependidikan, magang industri (dikenal dengan PPL) dilakukan tiga kali, mulai dari semester dua, sedangkan untuk jurusan/prodi nonkependidikan, magang hanya dilakukan satu kali. Model magang industri yang tepat guna mencapai standar kompetensi lulusan belum ada di Fakultas Ekonomi Universitas Negeri Yogyakarta. Agar program magang industri ini dapat berjalan sesuai dengan tujuannya, maka diperlukan satu model magang industri yang tepat bagi Fakultas Ekonomi. Berdasarkan latar belakang tersebut maka diperlukan suatu kajian untuk mengembangkan model magang industri bagi jurusan nonkependidikan.

Tujuan penelitian ini adalah mencari model magang industri yang tepat guna mencapai standar kompetensi lulusan Fakultas Ekonomi Universitas Negeri Yogyakarta. Manfaat praktis dari penelitian ini adalah diperoleh model magang industri yang tepat untuk mencapai standar kompetensi lulusan Fakultas Ekonomi Universitas Negeri Yogyakarta.

Praktik magang dilakukan untuk membantu pekerja menjadi lebih terampil melaksanakan pekerjaannya. Praktik magang telah dilaksanakan sejak lama, bahkan pada masa pra-industri telah dilaksanakan. Berdasarkan tipe magang, dapat dijelaskan sebagi berikut: a) masterapprentice adalah proses memperoleh keahlian dan ketrampilan melalui transfer pengetahuan dan ketrampilan dari seorang ahli. Tipe ini muncul sebelum masa industri dan fokus magang tipe ini terletak pada ahli yang dijadikan narasumber; b) Mentoring adalah proses membentuk dan memelihara hubungan pengembangan antara senior (mentor) dengan junior (mentee). Tipe mentor apprentice adalah tipe magang yang melibatkan hubungan pengembangan antara senior (mentor) dengan junior (mentee). Sakamoto dan Tamanyu (2014) menegaskan bahwa siswa seharusnya tidak hanya mengekor pada akademisi (seperti pada tipe master apprentice) tetapi juga harus berperan aktif dalam memperluas pengetahuan dan keahlian mereka melalui perancah (scaffolding) yang tepat. Spark, Ingram, dan Phillips (2009) juga menegaskan bahwa kemitraan pelatihan (training partnership) atau mentoring apprentice terbukti dapat meningkatkan ketrampilan yang diperlukan; c) cognitive apprentice ini didasari dari teori pembelajaran social yang dikembangkan oleh Bandhura pada tahaun 1986. Pada tipe ini magang (proses memperoleh mendapatkan pengetahuan dan ketrampilan) diperoleh melalui melihat tingkat laku orang lain. Calon profesional akan belajar meniru tingkah laku atau dalam hal tertentu menjadikan orang lain sebagai model baginya. Proses modeling (peniruan) ini diawali dengan proses kognitif internal, memahami bagaimana belajar dari orang lain tanpa dipengaruhi lingkungan; d) sandwich, proses pembelajaran model Sandwich diawali dengan berlangsungnya pembelajaran di dalam kelas (teori) dalam kurun waktu tertentu, selanjutnya siswa/mahasiswa akan menjalani proses magang selama kurun waktu tertentu untuk menerapkan teori yang didapatkan di kelas untuk diimplementasikan dalam dunia kerja dan dunia industri (DUDI) kemudian, siswa/mahasiswa akan membuat laporan serta melaporkannya proses magang yang telah dialami. Pembelajaran di tempat kerja (Sandwich) merupakan suatu metode pembelajaran yang terstruktur dimana seseorang siswa/mahasiswa (mentee) selain belajar di kelas, siswa/mahasiswa (mentee) 
diminta untuk bekerja secara nyata di suatu perusahaan atau organisasi dalam suasana kerja yang sesungguhnya. Dengan pembelajaran seperti ini, mentee belajar dan memperoleh pengalaman nyata dari proses pekerjaan yang mereka alami dengan disupervisi oleh tutor akademik dan supervisor di tempat kerja. Pembelajaran yang diperoleh di kelas menjadi lebih matang dengan tambahan aktivitas bekerja secara nyata di perusahaan.

Peni Handayani (2013) menjelaskan bahwa terdapat beberapa aspek kunci dalam pengembangan magang, yaitu: aspek konteks, aspek desain kurikulum, aspek pengembangan skills dan aspek pengelolaan magang. Aspek konteks merujuk pada konteks belajar mengajar dan penerapan kurikulum pembelajaran yang disusun berdasarkan tingkat kesulitan (Dickens dan Arlett, 2009 dalam Peni Handayani, 2013). Finch dan Crunkilton (1999, dalam Peni Handayani, 2015) menjelaskan bahwa sebuah program atau kurikulum harus dikembangkan melalui proses atau serangkaian langkah. Pengembangan skills berfokus pada dua aspek, yaitu aspek kebutuhan industri dan aspek kepentingan mahasiswa pemagang. Dalam aspek kebutuhan industri banyak mensyaratkan lulusan dari sebuah perguruan tinggi dapat menunjukkan transferable skills, seperti kesadaran etika dan isu-isu berkaitan dengan lingkungan yang melekat terhadap atribut-atribut sebagai berikut: kemampuan analisis, refleksi, kritik dan sintesis, maupun personal skills uang baik (Dicken dan Arlett, 2009 dalam Peni Handayani, 2013). Magang indsutri sebagai bagian yang tidak terpisahkan dari kurikulum harus dikelola baik agar tujuannya tercapai. Oleh karena itu pengelolaan magang industri sebaiknya mengacu pada konsep manajemen berbasis sekolah (school based management).

\section{METODE PENELITIAN}

Penelitian ini termasuk dalam research and development ( $\mathrm{R} \& \mathrm{D})$. Penelitian ini bertujuan untuk menghasilkan produk tertentu, dan menguji keefektifan suatu produk (Sugiyono, 2010). Subjek dalam penelitian ini adalah 41 orang mahasiswa yang pernah/sedang menempuh magang (mahasiswa Akuntansi S1, Manajemen S1, Akuntansi D3, Pemasaran D3, dan Sekretari D3), stakeholder/user (dunia industri yang memakai lulusan), dan institusi perguruan tinggi. Adapun objek penelitian ini adalah model magang industri yang akan dilihat dari: tipe magang, kemampuan pembimbing dalam mensupervisi, kehadiran dosen, pembimbing magang di lapangan, durasi magang, kesesuaian kurikulum PT dengan kebutuhan dunia kerja, proses meliputi manajemen pengelolaan magang, dan produk meliputi pengembangan skills mahasiswa. Data penelitian ini terdiri dari dua jenis yaitu data kuantitatif dan kualitatif. Data kuantitatif berupa angka penilaian kecenderungan yang diperoleh dari angket validasi/penilaian magang yang sudah berlangsung (sudah dijalani) saat ini. Angket ini diberikan kepada mahasiswa.

Tabel 1. Indikator Instrumen Penelitian

\begin{tabular}{|c|c|}
\hline Variabel & Aspek \\
\hline \multirow{8}{*}{$\begin{array}{c}\text { Model } \\
\text { Magang } \\
\text { Industri } \\
\text { Guna } \\
\text { Peningkatan } \\
\text { Kompetensi } \\
\text { Lulusan }\end{array}$} & Tipe magang \\
\hline & $\begin{array}{l}\text { Kemampuan pembimbing } \\
\text { dalam mensupervisi, }\end{array}$ \\
\hline & Kehadiran dosen \\
\hline & $\begin{array}{lll}\text { Pembimbing } & \text { magang } \\
\text { lapangan }\end{array}$ \\
\hline & Durasi magang \\
\hline & $\begin{array}{l}\text { Kesesuaian kurikulum PT } \\
\text { dengan kebutuhan dunia } \\
\text { kerja. }\end{array}$ \\
\hline & $\begin{array}{l}\text { Proses meliputi manajemen } \\
\text { pengelolaan magang. }\end{array}$ \\
\hline & $\begin{array}{lr}\text { Produk } & \text { meliputi } \\
\text { pengembangan } & \text { skills } \\
\text { mahasiswa. } & \end{array}$ \\
\hline
\end{tabular}


Penelitian metode $\mathrm{R} \& \mathrm{D}$ ini akan dibagi menjadi beberapa tahap, yaitu: tahap perumusan masalah, pengumpulan informasi, desain model magang, validasi dan revisi model magang, serta terakhir tahap evaluasi model magang. Tahap awal (perumusan masalah) dimaksudkan untuk memperoleh gambaran terkait potensi dan masalah. Selanjutnya studi literatur dilakukan dalam rangka mengumpulkan informasi yang relevan. Berdasarkan studi literatur dan pengumpulan informasi pendukung lainnya, dilakukan desain program magang industri. Desain model magang industri yang sudah disusun selanjutnya divalidasi dan direvisi (bilamana perlu). Pada penelitian ini, tahapan penelitian dilakukan sampai dengan tahap desain dan uji validasi.

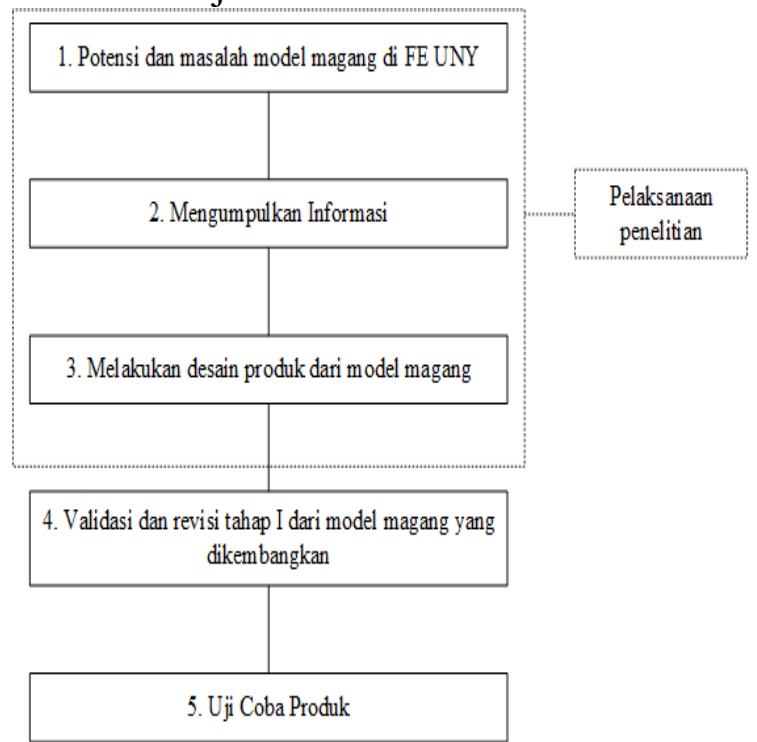

Gambar 1. Paradigma Penelitian

\section{HASIL PENELITIAN \\ PEMBAHASAN \\ Hasil Penelitian}

DAN

Jumlah sampel mahasiswa sebanyak 41 orang yang berasal dari berbagai perguruan tinggi di DIY baik negeri maupun swasta. Responden yang berasal dari UNY sebanyak 39\%, UGM sebesar 46\%, UII sebesar 2\%, AA/STIE YKPN sebesar 5\%, dan sisanya $\& \%$ berasal dari PTN/PTS lainnya. Lebih mendalam, durasi magang yang pernah dialami oleh responden adalah sebagai berikut: resonden yang mengikuti magang selama 1 bulan sebanyak $2 \%$, responden yang mengikuti magang selama 2 bulan sebesar 67\%, responden yang mengikuti magang selama 3 bulan sebanyak $29 \%$, dan sisanya $2 \%$ mengikuti magang lebih dari 3 bulan. Adapun Keseusaian Magang dengan Tempat Magang menunjukkan hasil bahwa $80 \%$ mahasisws yang mengikuti magang merasa tempat magang sesuai dan sisanya $20 \%$ menyatakan tempat magang tidak sesuai dengan bidang keahilannya.

\section{Potensi Masalah}

Potensi dan masalah yang ditemukan pada Fakultas Ekonomi Universitas Negeri Yogyakarta antara lain:

a. Belum tersedianya model magang industri di Fakultas Ekonomi Universitas Negeri Yogyakarta.

b. Belum ada pedoman penyelenggaraan program magang industri di Fakultas Ekonomi Universitas Negeri Yogyakarta, sehingga pelaksanaannya bervariasi antara satu jurusan dengan jurusan yang lainnya.

c. Belum ada model magang industri yang tepat guna mencapai standar kompetensi lulusan di Fakultas Ekonomi Universitas Negeri Yogyakarta.

\section{Mengumpulkan Informasi}

a. Kondisi magang yang ada

Tabel 2. Persentase Kesesuaian Kondisi Magang yang Ada dengan Model/Tipe Magang

\begin{tabular}{|l|l|c|}
\hline \multicolumn{1}{|c|}{$\begin{array}{c}\text { Tipe } \\
\text { Magang }\end{array}$} & Karakteristik & $\begin{array}{c}\text { Persen- } \\
\text { tase }\end{array}$ \\
\hline $\begin{array}{l}\text { Master } \\
\text { Apprentice }\end{array}$ & $\begin{array}{l}\text { Pemagang } \\
\text { didampingi oleh } \\
\text { seorang ahli di } \\
\text { bidangnya. }\end{array}$ & $73 \%$ \\
\hline
\end{tabular}




\begin{tabular}{|c|c|c|}
\hline $\begin{array}{c}\text { Tipe } \\
\text { Magang }\end{array}$ & Karakteristik & $\begin{array}{c}\text { Persen- } \\
\text { tase }\end{array}$ \\
\hline & $\begin{array}{l}\text { Pendampingan } \\
\text { dari tenaga ahli } \\
\text { dianggap dapat } \\
\text { metnransfer } \\
\text { pengetahuan } \\
\text { dan } \\
\text { keterampilan. }\end{array}$ & $83 \%$ \\
\hline $\begin{array}{l}\text { Cognitif } \\
\text { Apprentice }\end{array}$ & $\begin{array}{l}\text { Pemagang } \\
\text { melakukan } \\
\text { pengamatan } \\
\text { kondisi } \\
\text { lingkungan } \\
\text { tempat magang } \\
\text { untuk } \\
\text { melakukan } \\
\text { pekerjaan. }\end{array}$ & $80 \%$ \\
\hline Sandwich & $\begin{array}{l}\text { Pemagang } \\
\text { dituntut untuk } \\
\text { membuat } \\
\text { laporan magang } \\
\text { setelah proses } \\
\text { magang selesai. }\end{array}$ & $83 \%$ \\
\hline
\end{tabular}

Sumber: Data Diolah

Tabel 2 menjelaskan bahwa kesesuaian jenis magang ini di lapangan sebesar $73 \%$ terkait dengan mengharuskan pemagang didampingi oleh seorang yang ahli di bidangnya. Adapun kesesuaian jenis magang ini di lapangan terkait dengan pendampingan dari tenaga ahli dianggap dapat mentransfer pengetahuna dan keterampilan sebesar $83 \%$. Responden juga menilai kesuaian magang yang ada di lapangan sekarang dengan tipe cognitif apprentice sebesar $80 \%$. Pada tipe cognitive apprentice, pemagang melakukan pengamatan kondisi lingkungan tempat magang untuk melakukan pekerjaan. Untuk tipe sandwich dinilai oleh responden memiliki kesesuaian dengan kondisi magang yang ada sekarang sebesar $83 \%$. b. Magang yang diinginkan

Tabel 3. Magang yang Diinginkan

\begin{tabular}{|l|c|}
\hline \multicolumn{1}{|c|}{ Tipe Magang } & $\begin{array}{c}\text { Nilai Rata- } \\
\text { rata }\end{array}$ \\
\hline Master Apprentice & $74 \%$ \\
\hline Mentor Apprentice & $65 \%$ \\
\hline Cognitif Apprentice & $78 \%$ \\
\hline Sandwich & $94 \%$ \\
\hline
\end{tabular}

Sumber: Data Diolah

Tabel 3 menjelaskan bahwa tipe magang yang paling banyak diinginkan oleh responden adalah tipe sandwich. Di mana proses magang menitikberatkan pada penerapan teori yang didapatkan pemagang di dalam kelas kemudian diterapkan di lapangan dengan supervisi/bimbingan dari narasumber.

\section{Desain Produk (Magang yang Diusulkan)}

a. Aspek konteks

Tabel 4. Aspek Tipe Magang, Kemampuan Pembimbing dalam Mensupervisi, Kehadiran Dosen, Pembimbing Magang di Lapangan, dan Durasi Magang

\begin{tabular}{|c|l|c|}
\hline \multirow{1}{*}{ Aspek } & \multicolumn{1}{|c|}{ Penilaian } & $\begin{array}{l}\text { Per- } \\
\text { sen- } \\
\text { tase }\end{array}$ \\
\hline \multirow{5}{*}{ Tipe Magang } & $\begin{array}{l}\text { Model magang } \\
\text { yang } \\
\text { diterapkan } \\
\text { mempengaruhi } \\
\text { keterampilan } \\
\text { yang dikuasai }\end{array}$ & \\
\cline { 2 - 2 } & $\begin{array}{l}\text { Kemudahan } \\
\text { dalam mencari } \\
\text { tempat magang } \\
\text { yang sesuai } \\
\text { dengan bidang } \\
\text { keahlian }\end{array}$ & \\
& 92\% \\
& sangat penting & \\
\cline { 2 - 2 } & $\begin{array}{l}\text { Pembekalan } \\
\text { yang diberikan } \\
\text { pihak }\end{array}$ & \\
Perguruan & \\
\hline
\end{tabular}


Dyah Setyorini, dkk

$37-47$

\begin{tabular}{|c|c|c|}
\hline Aspek & Penilaian & $\begin{array}{l}\text { Per- } \\
\text { sen- } \\
\text { tase }\end{array}$ \\
\hline & $\begin{array}{l}\text { Tinggi } \\
\text { sebelum } \\
\text { melakukan } \\
\text { magang sangat } \\
\text { penting }\end{array}$ & \\
\hline $\begin{array}{l}\text { Kemampuan } \\
\text { Pembimbing } \\
\text { dalam } \\
\text { Mensupervisi }\end{array}$ & $\begin{array}{l}\text { Kemampuan } \\
\text { dosen } \\
\text { pembimbing } \\
\text { magang dalam } \\
\text { memberikan } \\
\text { supervisi } \\
\text { sangat penting }\end{array}$ & $88 \%$ \\
\hline $\begin{array}{l}\text { Kehadiran } \\
\text { Dosen }\end{array}$ & $\begin{array}{l}\text { Kehadiran } \\
\text { dosen } \\
\text { pembimbing } \\
\text { magang di } \\
\text { tempat magang }\end{array}$ & $83 \%$ \\
\hline \multirow{4}{*}{$\begin{array}{l}\text { Pembimbing } \\
\text { Magang di } \\
\text { Lapangan }\end{array}$} & $\begin{array}{l}\text { Kemampuan } \\
\text { dosen } \\
\text { pembimbing } \\
\text { magang dalam } \\
\text { membantu } \\
\text { memecahkan } \\
\text { masalah yang } \\
\text { dihadapi }\end{array}$ & \multirow{4}{*}{$93 \%$} \\
\hline & $\begin{array}{l}\text { Komposisi } \\
\text { penilaian hasil } \\
\text { magang harus } \\
\text { proposional } \\
\text { antara teori } \\
\text { dengan praktik }\end{array}$ & \\
\hline & $\begin{array}{l}\text { Transparansi } \\
\text { penilaian } \\
\text { dalam } \\
\text { memberikan } \\
\text { nilai akhir } \\
\text { sangat penting }\end{array}$ & \\
\hline & $\begin{array}{l}\text { Ketersediaan } \\
\text { waktu } \\
\text { bimbingan } \\
\text { yang diberikan } \\
\text { dosen } \\
\text { pembimbing } \\
\text { magang sangat } \\
\text { penting }\end{array}$ & \\
\hline
\end{tabular}

\begin{tabular}{|l|l|c|}
\hline Aspek & Penilaian & $\begin{array}{c}\text { Per- } \\
\text { sen- } \\
\text { tase }\end{array}$ \\
\hline $\begin{array}{l}\text { Durasi } \\
\text { Magang }\end{array}$ & $\begin{array}{l}\text { Durasi magang } \\
\text { mempengaruhi } \\
\text { keterampilan } \\
\text { yang akan } \\
\text { dikuasai }\end{array}$ & $88 \%$ \\
\hline
\end{tabular}

\section{Sumber: Data Diolah}

Tabel 4 menjelaskan bahwa dari 41 responden $92 \%$ beranggapan bahwa tipe magang, kemudahan dalam mencari tempat magang dan pembekalan yang diberikan Perguruan Tinggi sebelum melakukan magang memiliki peranan penting bagi pemagang.

Kemudian, $88 \%$ responden beranggapan bahwa kemampuan pembimbing dalam memberikan supervisi memiliki peranan penting bagi pemagang. Selain itu, $83 \%$ responden beranggapan bahwa kehadiran dosen pembimbing magang di tempat magang memiliki peranan penting bagi pemagang. Dilihat dari kemampuan dosen pembimbing magang dalam membantu memecahkan masalah, komposisi penilaian magang yang proposional, transparansi penilaian magang dan ketersediaan waktu bimbingan, $93 \%$ responden beranggapan bahwa hal tersebut memiliki peranan penting bagi pemagang. Hal ini terkait dengan pengawasan pemagang, membantu pemagang dalam pemecahan masalah serta memberikan bimbingan dan arahan pemagang selama melakukan proses magang.

Terkait dengan penguasaan keterampilan pemagang, $88 \%$ responden beranggapan durasi magang juga berperan penting. Durasi magang dapat berpengaruh pada keterampilan yang akan dikuasai oleh pemagang, jika durasi magang terlalu singkat maka dimungkinkan pemagang belum dapat 
mengusai keterampilan. Sedangkan, jika durasi magang terlalu lama maka dimungkinkan pemagang merasa jenuh.

b. Aspek kurikulum

Tabel 5. Aspek Kurikulum

\begin{tabular}{|c|c|c|c|}
\hline Kategori & $\begin{array}{c}\text { Inter- } \\
\text { val }\end{array}$ & $\begin{array}{c}\text { Freku- } \\
\text { ensi }\end{array}$ & $\begin{array}{c}\text { Persen } \\
\text { tase }\end{array}$ \\
\hline Rendah & $<16$ & 12 & $29 \%$ \\
\hline Sedang & $16-20$ & 16 & $39 \%$ \\
\hline Tinggi & $>20$ & 13 & $32 \%$ \\
\hline \multicolumn{2}{|c|}{ Jumlah } & $\mathbf{4 1}$ & $\mathbf{1 0 0 \%}$ \\
\hline
\end{tabular}

Sumber: Data Diolah

Tabel 5 menjelaskan bahwa nilai kencenderungan aspek kurikulum model magang yang diinginkan, di mana nilai kencenderungan rendah berada pada interval kurang dari 16 dengan frekuensi 12 reponden (29\%), sedang berada pada interval $16-20$ dengan frekuensi 16 responden $(39 \%)$ dan tinggi pada interval lebih dari 20 dengan frekuensi 13 responden $(32 \%)$.

c. Aspek pengelolaan magang

Tabel 6. Aspek Pengelolaan Magang

\begin{tabular}{|c|c|c|c|}
\hline Kategori & Interval & $\begin{array}{c}\text { Freku- } \\
\text { ensi }\end{array}$ & $\begin{array}{c}\text { Persen- } \\
\text { tase }\end{array}$ \\
\hline Rendah & $<16$ & 2 & $5 \%$ \\
\hline Sedang & $16-24$ & 23 & $56 \%$ \\
\hline Tinggi & $>24$ & 16 & $39 \%$ \\
\hline \multicolumn{2}{|c|}{ Jumlah } & $\mathbf{4 1}$ & $\mathbf{1 0 0 \%}$ \\
\hline
\end{tabular}

Sumber: Data Diolah

Tabel 6 menjelaskan bahwa nilai kencenderungan aspek pengelolaan magang model magang yang diinginkan, di mana nilai kencenderungan rendah berada pada interval kurang dari 16 dengan frekuensi 2 reponden (5\%), sedang berada pada interval $16-24$ dengan frekuensi 23 responden $(56 \%)$ dan tinggi pada interval lebih dari 24 dengan frekuensi 16 responden (39\%). d. Aspek pengembangan skill Tabel 7. Aspek Pengembangan Skill

\begin{tabular}{|c|c|c|c|}
\hline Kategori & Interval & Frekuensi & $\begin{array}{c}\text { Persen- } \\
\text { tase }\end{array}$ \\
\hline Rendah & $<18,7$ & 2 & $5 \%$ \\
\hline & $18,7-$ & & \\
Sedang & 23,3 & 20 & $49 \%$ \\
\hline Tinggi & $>23,3$ & 19 & $46 \%$ \\
\hline \multicolumn{2}{|c|}{ Jumlah } & 41 & $\mathbf{1 0 0 \%}$ \\
\hline
\end{tabular}

Sumber: Data Diolah

Tabel 8 menjelaskan bahwa nilai kencenderungan aspek pengembangan skill model magang yang diinginkan, di mana nilai kencenderungan rendah berada pada interval kurang dari 18,7 dengan frekuensi 2 reponden $(5 \%)$, sedang berada pada interval 18,7 - 23,3 dengan frekuensi 20 responden (49\%) dan tinggi pada interval lebih dari 23,3 dengan frekuensi 19 responden (46\%).

\section{Pembahasan}

Berdasarkan hasil penelitian, maka dapat diindikasikan bahwa tipe magang yang responden pernah dilakasanakan mendekati dengan tipe magang master apprentice, di mana proses magang yang dititikberatkan pada ahli yang dijadikan sebagai narasumber bagi pemagang. Tipe ini, diharapkan pemagang memperoleh keahlian dan keterampilan melalui transfer pengetahuan dan keterampilan dari seorang ahli. Dalam hal ini, tipe magang yang pernah dilakukan oleh responden lebih pada pendampingan seorang tenaga ahli dalam bidangnya untuk memperoleh transfer pengetahuan dari tenaga ahli tersebut. Selanjutnya, tipe magang yang diinginkan berdasarkan karakteristiknya didominasi oleh model sandwich.

Pengembangan model magang di FE UNY didasarkan berdasarkan aspek kunci, yaitu:

1. Pada aspek tipe magang, diperoleh bahwa magang yang selama ini telah dilakukan adalah master apprentice sedangkan tipe magang yang diinginkan adalah tipe sandwich. Selain itu, 
kemampuan dosen dalam melakukan supervisi pemagang, kehadiran dosen dan pembimbing magang di lapangan juga dianggap sebagai aspek yang cukup dipertimbangkan. Hal lainnya yang dianggap menjadi aspek penting dalam mengembangkan model magang adalah memperhitungkan waktu durasi magang. Tipe magang yang diterapkan oleh Perguruan Tinggi dianggap dapat mempengaruhi keterampilan yang akan dikuasai oleh pemagang, sehingga pengembangan tipe magang sebaiknya memperhatikan faktor-faktor lainnya yang dianggap dapat berpengaruh.

2. Kesesuaian kurikulum PT dengan kebutuhan dunia kerja menunjukkan kencenderungan sedang ke tinggi. Artinya, responden berpandangan bahwa desain kurikulum memegang peranan penting dalam melakukan pengembangan model magang. Di mana kurikulum dapat dikatakan sebagai sebuah pedoman pelaksanaan dari mata kuliah, sehingga penyusunan kurikulum sesuai kebutuhan dunia kerja merupakan hal yang dianggap penting. Kurikulum dianggap sebagai aspek kunci dikarenakan kurikulum merupakan sebuah pegangan dalam pelaksanaan matakuliah untuk mencapai tujuan dari matakuliah tersebut. Kesesuaian kurikulum PT dengan kebutuhan dunia kerja merupakan kebutuhan pokok yang harus diperhatikan oleh PT dalam penyusunan kurikulum untuk matakuliah magang. Hasil olah data menyebutkan bahwa aspek kurikulum memiliki kencederungan sedang ke tinggi. Artinya, responden berpandangan bahwa desain kurikulum memegang peranan penting dalam melakukan pengembangan model magang. Di mana kurikulum dapat dikatakan sebagai sebuah pedoman pelaksanaan dari mata kuliah, sehingga penyusunan kurikulum sesuai kebutuhan dunia kerja merupakan hal yang dianggap penting.

3. Manajemen pengelolaan magang menunjukkan kencenderungan dari sedang ke tinggi. Artinya, responden berpandangan bahwa pengelolaan magang oleh kampus memiliki peranan penting dalam menciptakan pelaksanan model magang yang akan dilaksanakan. Tanpa adanya manajemen pengelolaan magang yang baik, maka model magang yang diharapkan pun sulit terlaksana. Pengelolaan magang oleh kampus dianggap sebagai aspek kunci dikarenakan kampus sebagai jembatan penghubung antara tempat magang dan mahasiswa, sehingga manajemen pengelolaan magang yang dilakukan kampus memegang peranan penting dalam menciptakan model magang seperti yang diharapkan.

4. Setelah terjadinya aspek desain kurikulum, proses magang yang diselenggarakan oleh kampus (pengelolaan magang), maka selanjutnya adalah produk yang dihasilkan berupa pengembangan skill mahasiswa. Pengembangan skills mahasiswa menunjukkan kencenderungan dari sedang ke tinggi. Artinya adalah setelah dilakukannya proses magang, maka responden beranggapan bahwa terjadi pengembangan skill yang mereka miliki baik softskill maupun hardskill. Pengembangan skill dari mahasiswa dapat dianggap sebagai aspek kunci dikarenakan hasil akhir dari sebuah institusi pendidikan adalah lulusan yang berkompeten dan siap bersaing di dunia kerja. Pengembangan skills dianggap sebagai kebutuhan dan pertimbangan utama dalam melakukan pengembangan magang. 


\section{SIMPULAN DAN SARAN Simpulan}

Model magang yang selama ini ada didominasi oleh model master apprentice dengan kriteria sebagai berikut: pemagang didampingi oleh seorang ahli dibidangnya dan pendampingan dari tenaga ahli dianggap dapat metransfer pengetahuna dan keterampilan. Kemudian, magang yang diinginkan didominasi oleh model magang sandwich dengan kriteria sebagai berikut: Perguruan Tinggi memberikan materi yang dapat diterapkan di tempat magang dan perguruan Tinggi dapat mendatangkan tenaga ahli yang berkompeten agar pengalamannya dapat diterapkan pada saat magang. Berdasarkan hasil pembahasan diperoleh kesimpulan bahwa:

1. Model magang industri yang tepat untuk sesuai dengan standar kompetensi dilihat dari aspek konteks adalah model magang yang menunjukkan kecenderungan mengarah dari sedang ke tinggi. Mencerminkan bahwa responden beranggapan bahwa metode magang, kemampuan pembimbing dalam mensupervisi, kehadiran dosen, pembimbing magang di lapangan, dan durasi magang memiliki peranan penting untuk menciptakan model magang yang sesuai.

2. Model magang industri yang tepat untuk sesuai dengan standar kompetensi dilihat dari aspek desain kurikulum adalah model magang yang menunjukkan kencenderungan sedang ke tinggi. Desain kurikulum memegang peranan penting sebagai dasar pengembangan model magang.

3. Model magang industri yang tepat untuk sesuai dengan standar kompetensi dilihat dari aspek pengembangan skills adalah model magang yang menunjukkan kencenderungan sedang ke tinggi. Pengelolaan magang oleh kampus memiliki peranan penting dalam menciptakan pelaksanan model magang yang akan dilaksanakan. Tanpa adanya manajemen pengelolaan magang yang baik, maka model magang yang diharapkan pun sulit terlaksana.

4. Model magang industri yang tepat untuk sesuai dengan standar kompetensi dilihat dari aspek pengelolaan magang adalah model magang yang menunjukkan kencenderungan sedang ke tinggi. Artinya adalah setelah dilakukannya proses magang, maka diharapkan terjadi pengembangan skill baik softskill maupun hardskill.

\section{Saran}

Berdasarkan kesimpulan, maka saran yang dapat diajukan adalah sebagai berikut:

1. Dalam melakukan pengembangan model magang sebaiknya FE UNY melakukan pengembangan model magang sandwich. Model tersebut dirasa dapat mencukupi kebutuhan dunia kerja dan dunia industri terhadap kebutuhan tenaga kerja yang berkompeten.

2. Dalam melakukan pengembangan model magang sebaiknya FE UNY memperhatikan beberapa aspek kunci sebagai berikut: tipe magang, kemampuan pembimbing dalam mensupervisi, kehadiran dosen, pembimbing magang di lapangan, durasi magang, kesesuaian kurikulum PT dengan kebutuhan dunia kerja, proses meliputi manajemen pengelolaan magang, dan produk meliputi pengembangan skills mahasiswa.

3. Perlu dilakukan validasi model magang sebelum model magang yang diterapkan.

\section{DAFTAR PUSTAKA}

Douglas J, Alex D, \& Barry B. 2006. Measuring Student Satisfaction at a UK university.Quality Assurance in Education Journal, Vol. 14, No. 3. Emerald Group Publishing Limited. Henry M. Levin. 2006. What Is A World Class University? Conference of the 
Comparative \& International Education Society, Honolulu, Hawaii, diunduh dari http://www.tc.columbia.edu/centers/co ce/pdf_files/c12.pdf pada tanggal 8 April 2014.

Peni Handayani (2013). Model magang Mahasiswa Politeknik yang Diarahkan pada Pencapaian Standar Kompetensi Jenjang KKNI untuk Profesi Bidang Rekayasa. Disertasi. Yogyakarta: Program Pascasarjana, Universitas Negeri Yogyakarta.

Peni Handayani. (2015). Finding the Missing Link in the Design of Polytechnics Competence-Based Curriculum. Jurnal Publikasi. http://eprints.uny.ac.id/24459/1/A23.pdf pada 31 Juli 2015 06:53.

Sakamoto, Mitsuyo and Lumi Tamanyu (2014). "Mentorship in a Japanese graduate school: learning through apprenticeship", International Journal of Mentoring and Coaching in Education, Vol. 3 Iss: 1, pp.32 - 50 .

Spark, Alan, Hadyn Ingram, and Sunny Phillips (2009). "Advanced entry adult apprenticeship training scheme: a case study", Education + Training, Vol. 51 Iss: 3, pp.190 - 202

Sugiyono. (2010). Metode Penelitian Pendidikan. Bandung: CV Alfabeta. 